\title{
EMPREENDEDORISMO SOCIAL FEMININO E MOTIVAÇÕES PARA CRIAR ORGANIZAÇÕES SOCIAIS: ESTUDO DE CASOS MÚLTIPLOS EM SERGIPE
}

DOI: 1014211/Rege.33217

Artigo recebido em:18/11/2014 Artigo aprovado em:29/06/2015

Vitor Hugo da Silva Vaz - Universidade Federal de Sergipe - UFS Rivanda Meira Teixeira - Universidade Federal de Sergipe - UFS ${ }^{2}$ Maria Elena Leon Olave - Universidade Federal de Sergipe - UFS

Resumo: O fenômeno da criação de organizações é considerado complexo pelo fato de os empreendedores e das organizações variarem muito em ambientes igualmente diversos. Neste sentido, o presente estudo tem o objetivo de analisar as motivações de mulheres para criar empreendimentos sociais. O método utilizado na pesquisa foi o de estudo de casos múltiplos e as evidências foram coletadas por meio de entrevistas semiestruturadas. Foram analisados três empreendimentos sociais criados por mulheres em Sergipe. A análise dos casos permitiu verificar os diversos motivos alegados pelas empreendedoras para criarem esses empreendimentos, com destaque aos fatores ambientais, influência familiar e a necessidade de ajudar ao próximo. É importante destacar também a contribuição de instituições de ensino e os movimentos sociais na estruturação inicial dessas organizações, bem como as associações de moradores como instituições incubadoras.

Palavras-chave: Empreendedorismo social; Empreendedorismo feminino; Organizações sociais.

\section{SOCIAL FEMALE ENTREPRENEURSHIP AND MOTIVATIONS TO CREATE SOCIAL ORGANIZATIONS: MULTIPLE CASES STUDY IN SERGIPE}

Abstract: The phenomenon of creation of organizations is considered complex by the fact that entrepreneurs and businesses vary widely in environments equally diverse. In this line, this study aims to analyze the motivations of woman for creating social organization. The method used in the research was a multiple case study and evidences were collected through semi-structured interviews. Three social enterprises that were created by women in Sergipe were analyzed. The analysis of the cases has shown that social entrepreneurs had many reasons to create social

\footnotetext{
${ }^{1}$ Endereço: Rua C, 85, Bloco 2, apto 03, Residencial Recanto dos Jaçanãs, Bairro São Conrado, Aracaju - SE, CEP: 49042-842. E-mail: vitorhugovaz22@hotmail.com

${ }^{2}$ E-mail: rivandateixeira@gmail.com

${ }^{3}$ E-mail: mleonolave@gmail.com

VAZ, V. H. S.; TEIXEIRA, R. M.; OLAVE, M. E. L. Empreendedorismo social feminino e motivações para criar organizações sociais: estudo de casos múltiplos em Sergipe. Revista de Empreendedorismo e Gestão de Pequenas Empresas, v.4, n.3, 2015.
} 
enterprises, with emphasis on environmental factors, family influence and the needed to help others. It is also important to highlight the contribution of educational institutions and social movements in the initial structuring of these organizations as well as residents' associations as incubators institutions.

Keywords: Social Entrepreneurship; Female entrepreneurship; Social organizations.

\section{Introdução}

As pesquisas sobre o empreendedorismo têm sido discutidas de várias formas pelos pesquisadores, principalmente com relação ao fenômeno de criação de organizações (GARTNER, 1989; LOW; MACMILLAN, 1988) e a forma pela qual as oportunidades para criar bens e serviços podem ser descobertas, avaliadas e exploradas (SHANE; VENKATARAMAN, 2000).

Só recentemente o empreendedorismo no contexto de promoção social atraiu o interesse de pesquisadores e ainda está emergindo como área de investigação acadêmica (AUSTIN; STEVENSON; WEI-SKILLERN, 2006). Para contribuir com o desenvolvimento dos estudos sobre o empreendedorismo social, Peredo e McLean (2006) destacam a necessidade de haver uma classificação distinta por ter focos diferentes e assim, representarem organizações diferentes.

Segundo Rossoni, Onozato e Horochovski (2006), os empreendedores sociais podem variar em função do gênero, sendo dado maior destaque aos homens. Entretanto, no desenvolvimento de ações sociais e, especialmente, em se tratando de empreendedorismo social, a participação feminina vem se destacando de forma acentuada (NISHIMURA; ALPERSTEDT; FEUERSHÜTTE, 2012). Para Humbert (2012), é reconhecida a escassez de estudos que consideram o gênero no empreendedorismo social.

Por tais razões, o presente estudo tem o objetivo de analisar as motivações de mulheres em criar empreendimentos sociais. Especificamente, pretende-se analisar as características dos empreendimentos sociais e identificar as principais motivações das empreendedoras para a criação dessas organizações.

Para atingir os objetivos propostos, inicialmente, será apresentada uma breve revisão da literatura sobre o empreendedorismo social. Logo após, será 
apresentada uma revisão da literatura acerca do empreendedorismo feminino e o processo de criação de organizações. Na sequência, a metodologia adotada no estudo é apresentada sendo seguida da descrição dos casos e análise comparativa. Por fim, serão apresentadas as considerações finais que apontam os principais resultados da pesquisa em questão.

\section{Empreendedorismo social}

É de verificar-se que o tema empreendedorismo já tem considerável espaço no meio acadêmico. Contudo, uma de suas vertentes, o empreendedorismo social, ainda recebe pouca atenção por parte dos pesquisadores (ROSSONI; ONOZATO; HOROCHOVSKI, 2006).

Para Austin, Stevenson e Wei-Skillern (2006), o condutor central do empreendedorismo social é o problema social a ser abordado. Neste caso, a forma de organização particular toma uma decisão sobre qual formato é mais eficaz para mobilizar os recursos necessários para resolver os problemas sociais. Assim, o empreendedorismo social tem por finalidade uma teoria explícita ou implícita de mudança (MAIR, 2010).

Como destacado por Ozonato e Teixeira (2010), no caso do Brasil, ainda é preciso conhecer melhor essas organizações e suas dificuldades, para desenvolver meios para apoiar e contribuir com suas ações. Peredo e McLean (2006) argumentam que se deve explorar, além de uma definição unificadora, as diferentes finalidades do empreendedorismo social.

Para Onozato e Teixeira (2010), é necessário analisar as principais atividades desenvolvidas durante a criação das organizações sociais. Rossoni, Onozato e Horochovski (2006) lembram também que é relevante analisar as motivações das pessoas que criam essas organizações.

Segundo Peredo e McLean (2006), os benefícios sociais podem ser o único objetivo da organização ou mesmo as metas sociais que estejam inseridas em algum lugar entre os objetivos organizacionais. O quadro 1 apresenta alguns tipos de empreendedorismo social:

VAZ, V. H. S.; TEIXEIRA, R. M.; OLAVE, M. E. L. Empreendedorismo social feminino e motivações para criar organizações sociais: estudo de casos múltiplos em Sergipe. Revista de Empreendedorismo e Gestão de Pequenas Empresas, v.4, n.3, 2015. 
Quadro 1 - Tipos de empreendedorismo social.

\begin{tabular}{|l|l|}
\hline \multicolumn{1}{|c|}{ LUGAR DE METAS SOCIAIS } & \multicolumn{1}{c|}{ PAPEL NA TROCA COMERCIAL } \\
\hline $\begin{array}{l}\text { Objetivos da empresa são exclusivamente } \\
\text { sociais. }\end{array}$ & No intercâmbio comercial. \\
\hline $\begin{array}{l}\text { Objetivos da empresa são exclusivamente } \\
\text { sociais. }\end{array}$ & $\begin{array}{l}\text { Alguns intercâmbios comerciais, quaisquer lucros } \\
\text { diretamente para o benefício social ("integrado") ou } \\
\text { de apoio às empresas ("complementar"). }\end{array}$ \\
\hline $\begin{array}{l}\text { Objetivos da empresa são principalmente } \\
\text { sociais, mas não exclusivamente. }\end{array}$ & $\begin{array}{l}\text { Intercâmbio comercial, os lucros, em parte, para } \\
\text { beneficiar o empresário e/ou os apoiantes. }\end{array}$ \\
\hline $\begin{array}{l}\text { Objetivos sociais são proeminentes entre } \\
\text { outros objetivos da empresa }\end{array}$ & $\begin{array}{l}\text { Intercâmbio comercial, o lucro-marketing para o } \\
\text { empresário e os outros é o objetivo forte. }\end{array}$ \\
\hline $\begin{array}{l}\text { Objetivos sociais estão entre os objetivos da } \\
\text { empresa, mas subordinado a outros. }\end{array}$ & $\begin{array}{l}\text { Intercâmbio comercial, o lucro-marketing para o o } \\
\text { empresário e os outros é o objetivo proeminente ou } \\
\text { principal. }\end{array}$ \\
\hline
\end{tabular}

Fonte: Adaptado de Peredo e McLean (2006).

Segundo Mair (2010), vários são os fenômenos que podem desencadear a criação de um empreendimento social. Neste caso, apesar de todos esses fenômenos abraçarem a dimensão do impacto social, eles diferem substancialmente em relação aos atores, contextos, mecanismos e teorias de mudança social.

No Quadro 2, é possível visualizar os principais fenômenos levados em consideração no empreendedorismo social:

Quadro 2 - Principais fenômenos discutidos de empreendedorismo social.

\begin{tabular}{|l|l|l|}
\hline \multicolumn{1}{|c|}{$\begin{array}{c}\text { FENÖMENO EM } \\
\text { ESTUDO }\end{array}$} & \multicolumn{1}{|c|}{ DESCRIÇÃO } & \multicolumn{1}{|c|}{ AUTORES CHAVE } \\
\hline $\begin{array}{l}\text { Empreendedorismo } \\
\text { comunitário }\end{array}$ & $\begin{array}{l}\text { A comunidade é o ator empreendedor e } \\
\text { beneficiário. Por exemplo, uma aldeia engajar- } \\
\text { se em café de comércio justo, agricultura e } \\
\text { venda. }\end{array}$ & $\begin{array}{l}\text { (Peredo and Chrisman, } \\
\text { 2006; Johannisson and } \\
\text { Nilsson, 1989) }\end{array}$ \\
\hline $\begin{array}{l}\text { Agentes de mudança } \\
\text { social }\end{array}$ & $\begin{array}{l}\text { Indivíduos que alteram a percepção do público } \\
\text { (específico) sobre questões sociais. Os } \\
\text { exemplos vão desde John Elkington, fundador } \\
\text { da sustentabilidade, para Bono, do Grupo U2. }\end{array}$ & $\begin{array}{l}\text { (Waddock and Post, } \\
\text { 1991; Drayton, 2002) }\end{array}$ \\
\hline $\begin{array}{l}\text { Empreendedores } \\
\text { institucionais }\end{array}$ & $\begin{array}{l}\text { Indivíduos ou organizações que alteram os } \\
\text { arranjos sociais e de desenvolvimento do } \\
\text { tecido dificultando institucional. }\end{array}$ & $\begin{array}{l}\text { (Mair and Martí, 2009; } \\
\text { Martí and Mair, 2009) }\end{array}$ \\
\hline $\begin{array}{l}\text { Empreendimentos } \\
\text { sociais }\end{array}$ & $\begin{array}{l}\text { Empreendimentos que oferecem um produto } \\
\text { ou serviço que cria benefício social ou } \\
\text { ambiental, tais como a produção e distribuição } \\
\text { de garrafas de água biodegradável. }\end{array}$ & $\begin{array}{l}\text { (Dorado 2006; Sharir } \\
\text { and Lerner, 2006) }\end{array}$ \\
\hline $\begin{array}{l}\text { Organizações } \\
\text { empresariais sem fins } \\
\text { lucrativos }\end{array}$ & $\begin{array}{l}\text { Organizações sem fins lucrativos que se } \\
\text { dedicam a atividades comerciais para criar um } \\
\text { fluxo de renda e aumentar a sustentabilidade } \\
\text { financeira. }\end{array}$ & $\begin{array}{l}\text { (Fowler, 2000; Frumkin, } \\
\text { 2002) }\end{array}$ \\
\hline Empresa social & $\begin{array}{l}\text { Formas organizacionais seguindo os princípios } \\
\text { de cooperativas. }\end{array}$ & $\begin{array}{l}\text { (Borzaga and Defourny, } \\
\text { 2001) }\end{array}$ \\
\hline A inovação social & $\begin{array}{l}\text { Inovação entendida em sentido lato, incluindo } \\
\text { processos e tecnologia para o bem social. }\end{array}$ & $\begin{array}{l}\text { (Alvord, Brown and } \\
\text { Letts, 2004; Phills, } \\
\text { Deiglmeier and Miller, } \\
\text { 2008) }\end{array}$ \\
\hline
\end{tabular}

Fonte: Adaptado de Mair (2010).

VAZ, V. H. S.; TEIXEIRA, R. M.; OLAVE, M. E. L. Empreendedorismo social feminino e motivações para criar organizações sociais: estudo de casos múltiplos em Sergipe. Revista de Empreendedorismo e Gestão de Pequenas Empresas, v.4, n.3, 2015. 
Com relação às pesquisas acadêmicas sobre o empreendedorismo social, Ozonato e Teixeira (2010) destacam que geralmente abordam as características empreendedoras dos fundadores e gestores das organizações sociais e as diferenças existentes do empreendedorismo convencional, destacando que não se encontram estudos que abordam especificamente o processo de criação dessas organizações.

\section{Empreendedorismo feminino}

A participação das mulheres no desenvolvimento da economia dos países, principalmente como proprietárias e gestoras de empresas, vem crescendo (GEM, 2012). Todavia, Datta e Gailey (2012) argumentam que, apesar do reconhecimento dado às mulheres como criadoras de empresas, esta atenção ocorreu de forma atrasada.

De acordo com a pesquisa apresentada pelo Global Entrepreneurship Monitor - GEM (2012), no Brasil, as mulheres ultrapassaram os homens à frente de empreendimentos em estágio inicial ou com menos de 42 meses de existência.

Para Machado et al. (2003), as principais motivações para empreender são: contribuir com o orçamento familiar, ter maior flexibilidade para conciliar a vida profissional com as tarefas de casa e a criação dos filhos. Birley (1989), seguindo o modelo de Cooper (1984), apresentou outras motivações.

A seguir, no Quadro 3, é possível visualizar as principais motivações atribuídas às mulheres para empreender: 
Quadro 3 - Principais motivações das mulheres para empreender.

\begin{tabular}{|l|l|}
\hline \multicolumn{1}{|c|}{ CATEGORIAS } & \multicolumn{1}{|c|}{ DEFINIÇŌES } \\
\hline $\begin{array}{l}\text { Influencia } \\
\text { antecedente }\end{array}$ & $\begin{array}{l}\text { Incorpora aspectos de fundo do empreendedor que afetam a motivação, } \\
\text { percepções, habilidades e conhecimentos. Eles incluem fatores genéticos, } \\
\text { influências familiares, educação e experiências de carreira anteriores. }\end{array}$ \\
\hline $\begin{array}{l}\text { Organização } \\
\text { Incubadora }\end{array}$ & $\begin{array}{l}\text { Descreve os tipos de organização para a qual o empresário trabalhou } \\
\text { imediatamente antes de sair que incluem localização geográfica, tipo de } \\
\text { habilidades e conhecimentos adquiridos, entre em contato com outros jovens } \\
\text { empresários, e experiência em um ambiente de pequena empresa. } \\
\text { Além disso, Cooper cita os conhecidos fatores "empurrar" e "puxar", tais como } \\
\text { perda de emprego (push) e desejo de independência (pull). }\end{array}$ \\
\hline Fatores ambientais & $\begin{array}{l}\text { Incluem condições econômicas (especialmente a disponibilidade de capital de } \\
\text { risco), modelos, e acesso a serviços de apoio. }\end{array}$ \\
\hline
\end{tabular}

Fonte: Adaptado de Cooper (1984, apud Birley, 1989).

Com relação à criação de empresas com foco social, dá-se maior ênfase aos estudos sobre os empreendedores (ROSSONI; ONOZATO; HOROCHOVSKI, 2006; GEM, 2005). Entretanto, no desenvolvimento de ações sociais e especialmente em se tratando de empreendedorismo social, a participação feminina vem crescendo de forma acentuada (NISHIMURA; ALPERSTEDT; FEUERSHÜTTE, 2012). Um dos fatores deste destaque é o fato de as mulheres buscarem por oportunidades em ambientes menos competitivos e que os resultados de suas ações se retratem na qualidade de vida (CALAS; SMIRCICH; BOURNE, 2009).

Para Nishimura, Alperstedt e Feuershütte (2012), uma das motivações das mulheres em serem empreendedoras sociais pode estar associada a um perfil de solidariedade, à paixão pelo que faz e à vontade de promover uma mudança social. Segundo essas autoras, o convívio com uma realidade dolorosa em comunidades rurais e o racismo também são motivos apontados pelas mulheres para criarem organizações sociais e, desta forma, proporcionar mudança social.

De acordo com Humbert (2012), as mulheres têm tido um impacto positivo na sociedade através do seu envolvimento no terceiro setor, colocando alguns temas, como crianças, família, saúde da mulher, violência e discriminação contra certos grupos da população sobre a agenda social. Todavia, segundo a autora, o discurso acadêmico confere aos empreendedores sociais, características extras, especiais, que destacam a importância do empenho e dedicação aos objetivos sociais.

VAZ, V. H. S.; TEIXEIRA, R. M.; OLAVE, M. E. L. Empreendedorismo social feminino e motivações para criar organizações sociais: estudo de casos múltiplos em Sergipe. Revista de Empreendedorismo e Gestão de Pequenas Empresas, v.4, n.3, 2015. 
Datta e Gailey (2012) destacaram que a opressão vivida por algumas mulheres em determinados países pode ter relação com o desejo de independência e o de contribuir para a melhoria das condições de vida de outras mulheres. Isto tem estreita relação com a criação de empreendimentos sociais. Todavia, para Nishimura, Alperstedt e Feuershütte (2012), existe uma barreira em potencial para que as mulheres desenvolvam empreendimentos sociais, provavelmente associada à maior necessidade de lutar pela sobrevivência. $O$ fato de os homens terem maior acesso ao meio político e possuir uma renda superior às das mulheres também é um fato relevante e se constitui como barreira.

Assim, devido à quantidade limitada de material sobre as mulheres como empreendedoras sociais e a grande quantidade de fatores desencadeantes para empreender socialmente, há a necessidade de se discutir sobre o papel das mulheres dentro do terceiro setor.

\section{Procedimentos metodológicos}

O estudo pode ser considerado qualitativo, pois é fundamentalmente interpretativo e permite ao pesquisador ter uma visão holística do fenômeno (CRESWELL, 2002). Também pode ser considerado um estudo exploratório e descritivo. O estudo é exploratório, pois deseja-se esclarecer a compreensão de um problema, mesmo quando não há certeza da natureza exata do problema (SAUNDERS; LEWIS; THORNILL, 2007). É descritivo, pois vai descrever as atividades desenvolvidas pelas empreendedoras na criação dos seus negócios.

Para alcançar o objetivo proposto, optou-se pelo estudo de casos como estratégia de pesquisa (GODOY, 1995). Segundo Yin (2001), tal estratégia é a mais adequada quando se colocam questões de pesquisa do tipo "como" e "por que". Nesta estratégia, o pesquisador tem pouco controle sobre o fenômeno estudado, pois se encontra inserido em algum contexto da vida real.

Com relação ao tipo de estudo de caso, optou-se pelo estudo de casos múltiplos. A escolha se justifica pelo fato de que o estudo de múltiplos casos se concentra na possibilidade de comparação contínua de dados, desde o início da

VAZ, V. H. S.; TEIXEIRA, R. M.; OLAVE, M. E. L. Empreendedorismo social feminino e motivações para criar organizações sociais: estudo de casos múltiplos em Sergipe. Revista de Empreendedorismo e Gestão de Pequenas Empresas, v.4, n.3, 2015. 
teoria com a coleta de dados dos casos estudados (EISENHARDT, 1989). De acordo com Yin (2001), as provas resultantes no estudo de casos múltiplos são consideradas mais convincentes e o estudo é visto como mais robusto.

Nesta pesquisa, foram analisadas três organizações sociais: duas em comunidades de cidades do interior do Estado de Sergipe (Indiaroba e São Cristóvão) e uma em Aracaju. As instituições foram escolhidas por serem organizações sociais criadas por mulheres.

Para a coleta das evidências, foram adotadas as entrevistas semiestruturadas, um dos principais métodos de coleta de informações em um estudo de caso (YIN, 2001). Essas entrevistas também fornecem a oportunidade de sondar respostas, nas quais os entrevistados podem explicar ou construí-las. Podem, também, levar a discussão para as áreas em que o pesquisador não tinha considerado anteriormente e, consequentemente, contribuir para a profundidade na pesquisa. As entrevistas foram gravadas para fins de garantir a fidelidade da transcrição de todos os fatos relatados.

Para a análise dos casos, foi realizada, inicialmente, a descrição de cada caso individualmente e em seguida, a análise comparativa dos casos, com base na cross-case analysis (EISENHARDT, 1989). A comparação permite uma visão sinérgica das evidências e promove perspectivas divergentes.

As categorias analíticas do estudo foram definidas a partir dos objetivos e da revisão teórica sobre o tema. No quadro 4 pode-se observar as categorias utilizadas com os respectivos elementos de análise.

VAZ, V. H. S.; TEIXEIRA, R. M.; OLAVE, M. E. L. Empreendedorismo social feminino e motivações para criar organizações sociais: estudo de casos múltiplos em Sergipe. Revista de Empreendedorismo e Gestão de Pequenas Empresas, v.4, n.3, 2015. 
Quadro 4 - Categorias e Elementos de Análise Utilizados na Pesquisa.

\begin{tabular}{|c|c|}
\hline CATEGORIAS & $\begin{array}{l}\text { ELEMENTOS DE ANÁLISE } \\
\end{array}$ \\
\hline $\begin{array}{l}\text { Características dos } \\
\text { Empreendimentos sociais } \\
\text { (PEREDO; MCLEAN, 2006). }\end{array}$ & $\begin{array}{ll} & \text { Nome } \\
& \text { Número de funcionários } \\
\text { - } & \text { Tempo de existência } \\
\text { - } & \text { Tipo de Organização Social } \\
\end{array}$ \\
\hline $\begin{array}{l}\text { Motivos para criar a organização. } \\
\text { (GARTNER, 1985; COOPER, 1984, } \\
\text { apud BIRLEY, 1989; MAIR, 2010; } \\
\text { NISHIMURA; ALPERSTEDT; } \\
\text { FEUERSHÜTTE, 2012). }\end{array}$ & $\begin{array}{ll}\text { - } & \text { Influência antecedente } \\
\text { - } & \text { Frganizaçãos incubados Ambientais } \\
\text { - } & \text { Barreiras } \\
\text { - } & \text { Perfil de solidariedade } \\
\text { - } & \text { Vontade de pre faz } \\
\end{array}$ \\
\hline
\end{tabular}

Fonte: Os autores (2015).

\section{Análise dos casos}

Após a descrição dos três casos, será apresentada a análise comparativa com base nas categorias analíticas definidas na metodologia.

\section{Caso 1: O Caso da Cooperativa de Doces Santa Salu - COOPERUNIDOCE}

A Cooperativa de Doces Santa Salu (COOPERUNIDOCE) é uma cooperativa de mulheres que fabricam os mais diversos tipos de doces. Está localizada no povoado Cabrita no Município em São Cristóvão, que representa um grande alicerce para a redução de desigualdade e oportunidade de geração de trabalho e renda para as mulheres da comunidade.

A organização é fruto da iniciativa da Dona Tânia Santos. Ela liderou um grupo de mulheres que compõem a cooperativa. Ela é conhecida por todos na comunidade como Dona Santaninha, uma respeitada doceira na região que cresceu e ficou conhecida pelos doces produzidos por sua mãe adotiva.

Dona Tânia tem 66 anos, 12 filhos e primeiro grau incompleto e não chegou a conhecer os pais. É importante destacar que, apesar de ter colocado todos os doze filhos para ajudá-la na fabricação dos doces quando eram jovens, nenhum deles quis seguir as atividades que a mãe realiza na comunidade. Todavia, a VAZ, V. H. S.; TEIXEIRA, R. M.; OLAVE, M. E. L. Empreendedorismo social feminino e motivações para criar organizações sociais: estudo de casos múltiplos em Sergipe. Revista de Empreendedorismo e Gestão de Pequenas Empresas, v.4, n.3, 2015. 
empreendedora social destacou que o fato de ter os filhos trabalhando com ela foi muito importante para a educação deles. Segundo a entrevistada, fabricava doces desde jovem, sendo influenciada por uma senhora que vivia na comunidade:

Toda vida fui voltada para esse trabalho. Produzia doces em casa desde os 11 anos. Aqui tinha muita fruta. Fruta em abundância. Goiaba, manga, caju [...] aí eu fazia doce para vender. Antigamente, tinha uma senhora aqui chamada dona Salu, e o marido dela, o Senhor Severo, que era administrador de uma fazenda daqui dessa região, gostava muito de doces. Ela fazia esses doces e foi quem ensinou as mulheres da comunidade. Os doces eram melhores, as frutas eram melhores naquela época.

A entrevistada relatou que antes de formar a cooperativa, as atividades de fabricação e a comercialização dos doces eram realizadas de forma bem artesanal. Tanto ela como as mulheres da comunidade enfrentavam grandes dificuldades para comercializar seus produtos:

Naquela época, não era que nem hoje, não tinha água, esgoto. Era tudo a céu aberto. Não tinha transporte, não tinha energia, não tinha barragem no Rio. [...] agente saia daqui da Cabrita e ia andando daqui até o Castelo Branco (Bairro de Aracaju) para vender os doces todos os dias. Eu acordava às três da manhã. A gente se reunia e ia vender os doces de porta em porta. O doce era bom e se fazia a freguesia.

Entretanto, apesar de ter grande influência de Dona Salu, moradora da comunidade, para iniciar a fabricação de doces, a entrevistada destacou que a iniciativa das moradoras da comunidade em se mobilizar para comercializar os doces de forma organizada se deu no momento em que não tinham mais a colaboração da pessoa que as ensinou a fazer os doces:

Teve um momento que dona Salu foi embora. Foi morar na Rua do Riachão (Centro de Aracaju). O marido morreu e aí eu não quis que morresse a cultura (de fazer doces), porque é uma cultura o doce nosso aqui. Aí comecei a fazer reunião, reunião, juntamente com as outras (mulheres da comunidade) e aí continuamos a fazer os doces. [...] vamos discutir sobre uma cooperativa, por que cooperativa é melhor por que é tudo junto. Ai umas aderiram e outras não aderiram. E aí nós temos nossa cooperativa, e é isso aí.

VAZ, V. H. S.; TEIXEIRA, R. M.; OLAVE, M. E. L. Empreendedorismo social feminino e motivações para criar organizações sociais: estudo de casos múltiplos em Sergipe. Revista de Empreendedorismo e Gestão de Pequenas Empresas, v.4, n.3, 2015. 
Segundo informações de Dona Santaninha, o primeiro esforço em reunir as mulheres da comunidade para realizar ações que contribuíssem com a mudança da realidade local, se retratou na estruturação de uma associação. Neste caso, a associação foi o primeiro passo para que a cooperativa existisse:

A associação foi fundada através de um centro social chamado Doutora Lúcia Curi, e aí quando eu me afastei um tempo, vi que não desenvolveu nada. Me afastei por que não concordava em como as coisas eram feitas. Aí eu vi que tinha a necessidade de voltar. Aí, depois de várias reuniões, mudamos a razão social para Associação Comunitária Resplandecer, que tem esse nome desde 1986.

Entretanto, apesar de ter tido grande influência de uma pessoa da comunidade que ensinou as mulheres a fazer doces e da grande quantidade de frutas na região, a entrevistada informou que ajudar as mulheres da comunidade foi o maior motivo de criar um empreendimento social:

O maior motivo foi que a gente vê a necessidade das mulheres da comunidade. Elas são muito carentes. Tem mulheres aqui que já rodou Aracaju toda realizando as atividades da cooperativa. A mulher tem que ter o seu negócio, ou sacoleira ou lanchonete. Emprego não tem, mas trabalho tem bastante.

Com relação ao sentimento que a entrevistada possui com relação à comunidade, além da necessidade de ajudar as mulheres, o sentimento que tem por todos que fazem parte do local contribui para a dedicação prestada às atividades da cooperativa:

Eu amo muito o que faço. Se tem duas ou três pessoas que têm alguma coisa comigo eu peço a Deus que perdoe. A comunidade toda me respeita e me ama. Todo mundo gosta de mim graças a Deus. Tudo o que eles precisarem de mim eu posso estender as mãos. Nós não podemos viver sem precisar dos outros. Quando a gente faz com amor é perfeito.

Apesar da grande responsabilidade com a comunidade e os sentimentos de amor e dedicação pelo que faz, a entrevistada destacou que nem tudo foi fácil para

VAZ, V. H. S.; TEIXEIRA, R. M.; OLAVE, M. E. L. Empreendedorismo social feminino e motivações para criar organizações sociais: estudo de casos múltiplos em Sergipe. Revista de Empreendedorismo e Gestão de Pequenas Empresas, v.4, n.3, 2015. 
criar e estruturar o empreendimento. A falta de recursos para estruturar a organização e até mesmo a resistência de algumas das pessoas da localidade foram os principais entraves:

A maior barreira foi que não tinha capital para estruturar, documentação, e as mulheres não tinham como ajudar também financeiramente, mas conseguimos ultrapassar essa barreira. Nós tivemos outra barreira às mulheres daqui também. Muitas têm ciúmes do sucesso dos outros. [...] a comunidade me ajudou no incentivo. Não é só dinheiro. Tinha gente que dava uma ideia numa reunião. Vamos mobilizar o povo e discutir o que tem que ser discutido.

A cooperativa foi formada em 2008. Neste caso, a organização foi formada pelo fato de a associação não possuir natureza jurídica que possibilitasse a comercialização dos seus produtos e a captação de recursos para o desenvolvimento da atividade de fabricação de doces. A associação contribuiu com ações ligadas à assistência da comunidade. Já a cooperativa contribuiu com o desenvolvimento das ações das mulheres doceiras.

Após a formação jurídica da organização, a entrevistada destacou que necessitou de orientação para processos de produção de doces de forma industrial e na organização de processos administrativos:

Teve um momento que procurei a Universidade (UFS) e tive a ajuda da professora Isaura, veio aqui conversar com a gente e ficamos incubadas pela incubadora (da UFS). Até hoje pedimos ajuda ao pessoal de lá. O pessoal de alimentos ajudou bastante na hora de fazer os doces, por que os doces têm que ter selo pra poder vender. A vigilância veio aqui ver o local onde a gente produz.

A entrevistada destacou que durante o processo de busca de informações para a formação da organização, houve o processo de mobilização de pessoas da comunidade para a formação do quadro de cooperados. Explicou-se que foi aberto um edital de convocação para pessoas interessadas que comunicaram o interesse, sendo feita uma assembleia para integrá-las, tanto ao quadro de cooperados, como na direção. Neste caso, o processo foi realizado desde que a organização foi formada, adotando o mesmo processo da associação que antecedeu a cooperativa.

VAZ, V. H. S.; TEIXEIRA, R. M.; OLAVE, M. E. L. Empreendedorismo social feminino e motivações para criar organizações sociais: estudo de casos múltiplos em Sergipe. Revista de Empreendedorismo e Gestão de Pequenas Empresas, v.4, n.3, 2015. 
No Quadro 5, é possível visualizar o resumo das categorias analíticas do caso apresentado:

Quadro 5 - Resumo do Caso 1.

\begin{tabular}{|l|l|l|}
\hline CATEGORIAS & $\begin{array}{l}\text { ELEMENTOS DE } \\
\text { ANÁLISE }\end{array}$ & Evidências do caso 1 \\
\hline \multirow{4}{*}{$\begin{array}{l}\text { Características do } \\
\text { social }\end{array}$} & Nome & COOPERUNIDOCES \\
\cline { 2 - 3 } & Número de funcionários & 39 funcionários \\
\cline { 2 - 3 } & Tempo de existência & 5 anos. \\
\cline { 2 - 3 } & $\begin{array}{l}\text { Tipo de Organização } \\
\text { Social }\end{array}$ & Cooperativa. \\
\cline { 2 - 3 } & Local & Povoado Cabrita - São Cristóvão \\
\hline \multirow{4}{*}{\begin{tabular}{l} 
Motivos para criar organização \\
\cline { 2 - 3 }
\end{tabular}} & Influência antecedente & Não. \\
\cline { 2 - 3 } & Organização incubadora & Não. \\
\cline { 2 - 3 } & Fatores Ambientais & Grande quantidade de frutas na região. \\
\cline { 2 - 3 } & Barreiras & $\begin{array}{l}\text { Falta de recursos financeiros e conhecimento } \\
\text { para criar a organização. }\end{array}$ \\
\cline { 2 - 3 } & Perfil de solidariedade & $\begin{array}{l}\text { Fazer parte da comunidade e vivenciar as } \\
\text { necessidades de outras mulheres. }\end{array}$ \\
\cline { 2 - 3 } & Paixão pelo que faz & Dedicação e paixão em promover a mudança. \\
\cline { 2 - 3 } & $\begin{array}{l}\text { Vontade de promover } \\
\text { uma mudança social }\end{array}$ & $\begin{array}{l}\text { Contribuir com a mudança social das mulheres } \\
\text { da região. }\end{array}$ \\
\hline
\end{tabular}

Fonte: Os autores (2015).

\section{Caso 2: O Caso da Sociedade Sergipana Monte Sião - SSMS}

A Sociedade Sergipana Monte Sião é uma entidade filantrópica sem fins lucrativos, que visa prestar assistência às famílias associadas, atuar frente à vulnerabilidade social na garantia dos direitos sociais e garantir acessibilidade a projetos de moradia popular. Por meio da Lei no 3.954, de 19 de agosto de 2010, a Sociedade Sergipana Monte Sião foi reconhecida pela Prefeitura Municipal de Aracaju como instituição de utilidade pública.

A referida entidade era conhecida como Associação de Moradores do Loteamento Paraíso do Sul, foi fundada em 3 de agosto de 2004, com sede na Igreja Evangélica Assembleia de Deus Missionário em Sergipe, situada na rua 38 no 173, loteamento Paraíso do Sul, bairro Santa Maria em Aracaju. 
No decorrer do ano acima citado, os membros da igreja Assembleia de Deus Missionário, que tinham sua sede e residência na ocupação Paraíso do Sul, observaram a necessidade de buscar a melhoria da qualidade de vida e moradia da comunidade na qual a igreja estava inserida. Assim, planejaram de forma organizada uma associação para darem início às reivindicações aos órgãos competentes para saná-las.

Em uma assembleia com os organizadores e associados, ocorreu a mudança na denominação da associação por meio de uma votação, que passou a se chamar Monte Sião Aracaju - Se. Essa sugestão foi dada por um dos fundadores, o pastor Raimundo Resende, pois se refere ao relato da Bíblia que faz menção ao um Monte chamado Sião em Jerusalém como um lugar firme e que não abala.

O objetivo da instituição, ainda em forma de associação de moradores, era a melhoria das condições de vida dos moradores do loteamento Paraíso do Sul e adjacências. Tinha-se como projeto primário a organização da infraestrutura do bairro, envolvendo saneamento básico, água canalizada e principalmente energia elétrica, pois a localização do bairro era irregular. Para isso foi preciso várias mobilizações dos moradores, contando em muitas delas com a participação intrínseca do Movimento Popular de Moradia de Sergipe (MPMS), o qual é filiado à União Nacional por Moradia Popular (UNMP) e à Central de Movimentos Populares de Sergipe (CMPS).

A entrevista foi realizada com a Senhora Maria de Fátima Barbosa Martins, fundadora e presidente da organização social. A Dona Fátima é pernambucana de nascimento, tem 59 anos de idade, mãe de três filhos e está terminando uma graduação em Gestão de Recursos Humanos. Entretanto, possui curso técnico em enfermagem, profissão que atuou por 19 anos e sete meses em instituições do estado e particular. Em visitas pelo interior de Sergipe, iniciou as atividades de atendimento médico em comunidades carentes no Programa de Assistência a Mulher do Estado de Sergipe, o Pró-Mulher, durante oito meses. 
Após trabalhar vários anos como enfermeira, a entrevistada destacou que fazia várias viagens ao interior. Com essas viagens, pôde vivenciar uma realidade muito dura de mulheres doentes por falta de cuidado e atenção:

O que ajudou a eu aflorar ainda mais foi a questão da saúde da mulher nos interiores. Vi as mulheres muito sofridas. Quando ia para Estância, nas visitas ao interior pelo Pró-mulher, vi uma situação precária da mulher. Muitas mulheres com câncer, com HPV, muita doença. Elas estavam muito abandonadas. Vi que era uma questão de orientação.

Entretanto, houve motivos diferentes que a estimularam a criar a organização social. O passo inicial foi dado ao ver seu pai tornar-se líder de uma associação de moradores:

Meu pai foi o primeiro presidente da Associação de Moradores do Conjunto Castelo Branco que era onde nós morávamos. Quando eu era pequena eu ia a algumas reuniões e via os trabalhos que eram realizados pela associação. Foi o primeiro contato com trabalhos sociais. Vi ele tirar dinheiro do próprio bolso para ajudar na associação. Esse foi o principal.

Todavia, a entrevistada destacou que o que a levou definitivamente a fundar um empreendimento social que contribuísse com a mudança dos moradores dessa localidade chamada Paraíso do Sul, no Bairro Santa Maria, em Aracaju foi o fato de os moradores da localidade não possuírem moradia e autorização para habitarem o local. Eles necessitavam de uma representação formal que realizasse ações para mudar tal realidade. Assim, antes de fundar a associação, ela foi uma das fundadoras da Associação de Moradores do Orlando Dantas e Adjacências AMORD:

Juntou a fome com a vontade de comer. Precisava ajudar os moradores que tinham problemas na vida e que perderam tudo e não tinham onde morar. Vinham de vários lugares. Aí eu estava numa ocupação no Paraíso do Sul, que fica no início do Santa Maria. Tinha muito tráfico de drogas, roubo e prostituição. Precisava mudar a realidade do povo. Algumas pessoas que conseguiram terreno, e que queriam vender, quiseram até me matar, botaram fogo na minha casa. Graças a Deus eu não estava lá. Fui protegida por Deus.

VAZ, V. H. S.; TEIXEIRA, R. M.; OLAVE, M. E. L. Empreendedorismo social feminino e motivações para criar organizações sociais: estudo de casos múltiplos em Sergipe. Revista de Empreendedorismo e Gestão de Pequenas Empresas, v.4, n.3, 2015. 
Porém, apesar de destacar a influência do pai, o trabalho assistencial com mulheres no interior e a realidade dos moradores da comunidade que vivia, a empreendedora social declarou que o pensamento de ajudar e se dedicar inteiramente às pessoas foi muito influenciador. A experiência da conturbada separação com o ex-marido também foi motivadora e significativa para reforçar sua decisão:

O motivo da maior dedicação ao que faço foi no momento em que me separei. Não especificamente a separação, mas o fato de eu me dedicar ao social, meu marido não me apoiou. Quando me tornei missionária ele também não gostou. Mas aí eu queria continuar o que eu já estava fazendo para ajudar as pessoas. Aí eu me entreguei completamente.

Com base na entrevista com a representante da Sociedade Sergipana Monte Sião, apresenta-se um resumo no Quadro 6:

Quadro 6 - Resumo do Caso 2:

\begin{tabular}{|c|c|c|}
\hline CATEGORIAS & $\begin{array}{l}\text { ELEMENTOS DE } \\
\text { ANÁLISE }\end{array}$ & Evidências do caso2 \\
\hline \multirow{5}{*}{$\begin{array}{l}\text { Características do } \\
\text { Empreendimento } \\
\text { social }\end{array}$} & Nome & Sociedade Sergipana Monte Sião. \\
\hline & $\begin{array}{l}\text { Número de } \\
\text { funcionários }\end{array}$ & 8 funcionários. \\
\hline & $\begin{array}{l}\text { Tempo de } \\
\text { existência }\end{array}$ & 9 anos. \\
\hline & $\begin{array}{l}\text { Tipo de } \\
\text { Organização Social }\end{array}$ & Associação. \\
\hline & Local & Centro de Aracaju \\
\hline \multirow{7}{*}{$\begin{array}{l}\text { Motivos para criar } \\
\text { a organização. }\end{array}$} & $\begin{array}{l}\text { Influência } \\
\text { antecedente }\end{array}$ & $\begin{array}{l}\text { Vivência com o pai líder de uma associação de } \\
\text { moradores; Separação do antigo companheiro; }\end{array}$ \\
\hline & $\begin{array}{l}\text { Organização } \\
\text { incubadora }\end{array}$ & Associação de Moradores do Orlando Dantas. \\
\hline & Fatores Ambientais & $\begin{array}{l}\text { Falta de moradia e acesso a políticas públicas da } \\
\text { população. }\end{array}$ \\
\hline & Barreiras & Dificuldades financeiras. \\
\hline & $\begin{array}{l}\text { Perfil de } \\
\text { solidariedade }\end{array}$ & Necessidade de ajudar ao próximo. \\
\hline & Paixão pelo que faz & $\begin{array}{l}\text { Satisfação em ajudar as pessoas e promover a } \\
\text { igualdade social. }\end{array}$ \\
\hline & $\begin{array}{l}\text { Vontade de } \\
\text { promover uma } \\
\text { mudança social }\end{array}$ & $\begin{array}{l}\text { Contribuir com que a população local tivesse acesso a } \\
\text { moradia e assistência do poder público. }\end{array}$ \\
\hline
\end{tabular}

Fonte: Os autores (2015).

VAZ, V. H. S.; TEIXEIRA, R. M.; OLAVE, M. E. L. Empreendedorismo social feminino e motivações para criar organizações sociais: estudo de casos múltiplos em Sergipe. Revista de Empreendedorismo e Gestão de Pequenas Empresas, v.4, n.3, 2015. 
Caso 3: O Caso da Associação das Catadoras de Mangaba de Indiaroba (ASCAMAI)

A Associação das Catadoras de Mangaba e Indiaroba (Ascamai) é uma organização sem fins lucrativos das mulheres extrativistas da mangaba em Sergipe. Foi criada em 2009, visando abrir espaço para que as catadoras pudessem, por meio de trabalho coletivo, fomentar ações ecologicamente sustentáveis e socialmente justas, capazes de promover seu desenvolvimento socioeconômico.

Em outubro de 2011, com a conquista do patrocínio da Petróleo Brasileiro S/A (PETROBRAS), através do Edital Público: Petrobrás, Desenvolvimento \& Cidadania 2010 (projeto Catadoras de Mangaba, Gerando Renda e Tecendo Vida em Sergipe), a Ascamai angariou recursos para desenvolver seu trabalho, que atualmente acontece em 24 comunidades de sete municípios sergipanos.

A mangaba nativa e os mariscos garantem a sobrevivência de dezenas de comunidades da região costeira do Estado. No entanto, a especulação imobiliária, a carcinicultura e a monocultura são desafios que estão comprometendo as vidas de milhares de pessoas, não somente sob o aspecto nutricional, mas também como fonte de renda dessas famílias.

Ao verificarem que as mangabeiras, reconhecidas como árvore símbolo do Estado de Sergipe, conforme Decreto Lei ํo 12.723, de 20 de Janeiro de 1992, estavam sistematicamente sendo arrancadas pelos projetos imobiliários e de monocultura, ou mortas pelos venenos derramados pelos tanques de carcinicultura, as mulheres reunidas no I Encontro das Catadoras de Mangaba de Sergipe, decidiram levantar sua voz e com ajuda de pesquisadores e das Quebradeiras de Coco Babaçu do Maranhão (Mota et al., 2008), realizaram, em 2007, o I Encontro das Catadoras de Mangaba. Assim, surgiu o Movimento das Catadoras de Mangaba de Sergipe (MCM).

A senhora Alícia Santana Salvador Morais é pescadora, tem 27 anos, Marisqueira e Catadora de Mangaba. Casada e mãe de cinco filhos, cursa o $3^{\circ}$ ano do curso de Pedagogia/Magistério. Os seus pais também são pescadores. Foi a fundadora e é atualmente presidente da Associação das Catadoras de Mangaba e

VAZ, V. H. S.; TEIXEIRA, R. M.; OLAVE, M. E. L. Empreendedorismo social feminino e motivações para criar organizações sociais: estudo de casos múltiplos em Sergipe. Revista de Empreendedorismo e Gestão de Pequenas Empresas, v.4, n.3, 2015. 
Indiaroba (Ascamai) e vice-presidente do Movimento das Catadoras de Mangaba de Sergipe.

No que diz respeito à comunidade, a entrevistada elucidou ter uma relação muito boa, mas salientou que a falta de envolvimento do poder público municipal restringe o crescimento e as melhores condições de vida da população local:

Acho que tenho uma relação muito boa. Acho que se a gente tivesse um apoio municipal, a relação era bem melhor. As pessoas misturam muito a política com a vida pessoal. Mas vejo que as pessoas acreditam muito no nosso trabalho. Quando eles veem uma pessoa lutando por elas, creio que ficam satisfeitas. Mas isso não deve ser uma luta só minha.

A vivência com as dificuldades da comunidade e o reconhecimento com o trabalho das catadoras foram destacadas pela entrevistada como os principais motivos para empreender socialmente. $O$ reconhecimento do trabalho das catadoras e a sobrevivência da mangabeira foram destacados pela entrevistada:

A influência maior de ajudar a comunidade tendo o reconhecimento que tem hoje, e o objetivo também das mulheres que colhem a mangaba. Antes as pessoas tomavam o sorvete, e tomavam por tomar. Esse trabalho tinha que ser reconhecido. Por trás daquele fruto, doce, tem um trabalho muito sério. Nós somos catadoras e marisqueiras [...] Nossa luta é para que haja a queda das cercas das mangabeiras, pois nós, Catadoras de Mangaba, somos as verdadeiras donas delas.

No Quadro 7 apresenta-se um resumo com base nas categorias analisadas e nas informações apresentadas pela entrevista da Associação das Catadoras de Mangaba de Indiaroba:

VAZ, V. H. S.; TEIXEIRA, R. M.; OLAVE, M. E. L. Empreendedorismo social feminino e motivações para criar organizações sociais: estudo de casos múltiplos em Sergipe. Revista de Empreendedorismo e Gestão de Pequenas Empresas, v.4, n.3, 2015. 


\begin{tabular}{|c|c|c|}
\hline \multicolumn{3}{|c|}{ Quadro 7 - Resumo do Caso 3: } \\
\hline CATEGORIAS & $\begin{array}{c}\text { ELEMENTOS DE } \\
\text { ANÁLISE }\end{array}$ & Evidências do caso 3 \\
\hline \multirow{5}{*}{$\begin{array}{l}\text { Características do } \\
\text { Empreendimento } \\
\text { social }\end{array}$} & Nome & $\begin{array}{l}\text { Associação das Catadoras de Mangaba e Indiaroba - } \\
\text { ASCAMAI }\end{array}$ \\
\hline & $\begin{array}{l}\text { Número de } \\
\text { funcionários }\end{array}$ & 34 associados e 11 funcionários. \\
\hline & $\begin{array}{l}\text { Tempo de } \\
\text { existência }\end{array}$ & 3 anos. \\
\hline & $\begin{array}{l}\text { Tipo de } \\
\text { Organização Social }\end{array}$ & Associação \\
\hline & Local & Povoado Pontal em Indiaroba. \\
\hline \multirow{7}{*}{$\begin{array}{l}\text { Motivos para criar } \\
\text { a organização }\end{array}$} & $\begin{array}{l}\text { Influência } \\
\text { antecedente }\end{array}$ & $\begin{array}{l}\text { A liderança de um presidente de cooperativa da região } \\
\text { que orientou sobre os benefícios da formalização da } \\
\text { organização. }\end{array}$ \\
\hline & $\begin{array}{l}\text { Organização } \\
\text { incubadora }\end{array}$ & $\begin{array}{l}\text { Associação de Moradores do Povoado pontal de } \\
\text { Indiaroba. }\end{array}$ \\
\hline & Fatores Ambientais & $\begin{array}{l}\text { A existência de recursos do ambiente que possibilitou } \\
\text { a realização das ações. }\end{array}$ \\
\hline & Barreiras & Falta de recursos e de conhecimento. \\
\hline & $\begin{array}{l}\text { Perfil de } \\
\text { solidariedade }\end{array}$ & $\begin{array}{l}\text { Ser uma catadora de mangaba e pescadora como os } \\
\text { pais e as mulheres da região. }\end{array}$ \\
\hline & Paixão pelo que faz & $\begin{array}{l}\text { Vontade de reconhecimento da importância das } \\
\text { catadoras e marisqueiras. }\end{array}$ \\
\hline & $\begin{array}{l}\text { Vontade de } \\
\text { promover uma } \\
\text { mudança social }\end{array}$ & $\begin{array}{l}\text { Contribuir com a mudança da realidade da população } \\
\text { e preservação das plantas produtoras de mangaba. }\end{array}$ \\
\hline
\end{tabular}

Fonte: Os autores (2015).

\section{Análise comparativa dos casos}

Com relação às caraterísticas das organizações sociais, foi possível perceber que mesmo sendo dois casos de associações e um caso de cooperativa, tanto no caso da COOPERUNIDOCES, como no da ASCAMAI, a sobrevivência da organização está atribuída à oferta de produtos para o mercado.

Já no caso da Sociedade Monte Sião, a oferta dos serviços só ocorre por meio de parcerias e da captação de recursos de projetos. No caso desta organização, mesmo o tempo de existência ser maior que nas outras organizações, a quantidade de funcionários é bem menor. Neste caso, a expansão do empreendimento pode estar associada à atividade que desempenha, diferente dos dois outros casos em que há a comercialização contínua de produtos e, assim, a circulação maior de recursos e de pessoas.

VAZ, V. H. S.; TEIXEIRA, R. M.; OLAVE, M. E. L. Empreendedorismo social feminino e motivações para criar organizações sociais: estudo de casos múltiplos em Sergipe. Revista de Empreendedorismo e Gestão de Pequenas Empresas, v.4, n.3, 2015. 
No Quadro 8 é apresentado um resumo da categoria características do empreendimento social:

Quadro 8 - Características dos empreendimentos sociais

\begin{tabular}{|c|l|l|l|}
\hline CATEGORIAS & COOPERUNIDOCES & $\begin{array}{l}\text { Sociedade Sergipana } \\
\text { Monte Sião }\end{array}$ & \multicolumn{1}{c|}{ ASCAMAI } \\
\hline \multirow{4}{*}{$\begin{array}{l}\text { Características do } \\
\text { Empreendimento } \\
\text { social }\end{array}$} & COOPERUNIDOCES & $\begin{array}{l}\text { Sociedade Sergipana } \\
\text { Monte Sião }\end{array}$ & $\begin{array}{l}\text { Associação das } \\
\text { Catadoras de Mangaba } \\
\text { e Indiaroba - ASCAMAI }\end{array}$ \\
\cline { 2 - 4 } & 39 funcionários & 8 funcionários & $\begin{array}{l}\text { 34 associados e 11 } \\
\text { funcionários }\end{array}$ \\
\cline { 2 - 4 } & 5 anos & 9 anos & 3 anos \\
\cline { 2 - 4 } & Cooperativa & Associação & Associação \\
\cline { 2 - 4 } & $\begin{array}{l}\text { Povoado Cabrita em } \\
\text { São Cristóvão }\end{array}$ & Centro de Aracaju & $\begin{array}{l}\text { Povoado Pontal em } \\
\text { Indiaroba }\end{array}$ \\
\hline
\end{tabular}

Fonte: Os autores (2015).

Sobre os motivos para criar a organização, foi possível perceber na COOPERUNIDOCES e na ASCAMAI que as empreendedoras sociais nasceram nas comunidades e vivenciaram desde o começo as dificuldades relacionadas à falta de oportunidades para o desenvolvimento econômico da população, principalmente para as mulheres. Esta informação tem relação com os estudos realizados por Calas, Smircich e Bourne (2009) e Nishimura, Alperstedt e Feuershütte (2012), que atribui o empreendedorismo social feminino à vivência com uma problemática social e à preocupação com a igualdade de oportunidades relacionadas ao gênero. Entretanto, no caso da Sociedade Monte Sião, a motivação inicial foi decorrente de problemas pessoais da empreendedora em um primeiro momento, e das dificuldades vividas por mulheres do interior.

Assim, os três casos mostram as dificuldades da população ou do ambiente. Esta informação diverge com o estudo de Rossoni, Onozato e Horochovski (2006), que atribui uma maior taxa de empreendedorismo social à visão de oportunidade além de pessoal e material.

Nos três casos, foi possível perceber que a falta de informação e recursos foram destacados como as principais dificuldades para a formalização das organizações. No Caso da COOPERUNIDOCES, a entrevistada declarou que

VAZ, V. H. S.; TEIXEIRA, R. M.; OLAVE, M. E. L. Empreendedorismo social feminino e motivações para criar organizações sociais: estudo de casos múltiplos em Sergipe. Revista de Empreendedorismo e Gestão de Pequenas Empresas, v.4, n.3, 2015. 
alguns moradores da comunidade também dificultaram o início do empreendimento social.

Esta informação diverge com a apresentada no estudo de Ozonato e Teixeira (2010), no qual as entrevistadas esclareceram que o processo de criação das organizações sociais é simples e que a maior dificuldade foi atribuída à manutenção do empreendimento. Todavia, as autoras destacaram a necessidade de programas para orientar os empreendedores para fortalecer as entidades existentes focados no treinamento gerencial.

Nos casos da COOPERUNIDOCES e da ASCAMAI, ficou clara uma grande contribuição de instituições ligadas ao Governo do Estado e de professores da Universidade Federal de Sergipe no processo de formalização das organizações. Todavia, no caso da ASCAMAI, a captação dos primeiros recursos foi primordial para a formalização e início das atividades da organização, diferentemente dos outros dois casos que iniciaram e só após a formalização conseguiram captar recursos.

No Quadro 9 é apresentado um resumo da categoria motivos de criar a organização: 
Quadro 9 - Motivos para criar a organização:

\begin{tabular}{|c|c|c|c|}
\hline CATEGORIA & COOPERUNIDOCES & $\begin{array}{c}\text { Sociedade } \\
\text { Sergipana Monte } \\
\text { Sião }\end{array}$ & ASCAMAI \\
\hline \multirow{7}{*}{$\begin{array}{l}\text { Motivos para } \\
\text { criar a } \\
\text { organização }\end{array}$} & $\begin{array}{l}\text { Nãoinformou influência } \\
\text { anterior. }\end{array}$ & $\begin{array}{l}\text { Vivência com o pai } \\
\text { líder de uma } \\
\text { associação de } \\
\text { moradores; } \\
\text { Separação do antigo } \\
\text { companheiro; }\end{array}$ & $\begin{array}{l}\text { A liderança de um presidente } \\
\text { de cooperativa da região que } \\
\text { orientou sobre os benefícios } \\
\text { da formalização da } \\
\text { organização. }\end{array}$ \\
\hline & $\begin{array}{l}\text { Não existiu organização } \\
\text { incubadora. }\end{array}$ & $\begin{array}{l}\text { Associação de } \\
\text { Moradores do } \\
\text { Orlando Dantas. }\end{array}$ & $\begin{array}{l}\text { Associação de Moradores do } \\
\text { Povoado pontal de Indiaroba. }\end{array}$ \\
\hline & $\begin{array}{l}\text { Grande quantidade de } \\
\text { frutas na região. }\end{array}$ & $\begin{array}{l}\text { Falta de moradia e } \\
\text { acesso a políticas } \\
\text { públicas da } \\
\text { população. }\end{array}$ & $\begin{array}{l}\text { A existência de recursos do } \\
\text { ambiente que possibilitou a } \\
\text { realização das ações. }\end{array}$ \\
\hline & $\begin{array}{l}\text { Falta de recursos } \\
\text { financeiros e } \\
\text { conhecimento para criar } \\
\text { a organização. }\end{array}$ & $\begin{array}{l}\text { Dificuldades } \\
\text { financeiras. }\end{array}$ & $\begin{array}{l}\text { Falta de recursos e de } \\
\text { conhecimento. }\end{array}$ \\
\hline & $\begin{array}{l}\text { Fazer parte da } \\
\text { comunidade e vivenciar } \\
\text { as necessidades de } \\
\text { outras mulheres. }\end{array}$ & $\begin{array}{l}\text { Necessidade de } \\
\text { ajudar ao próximo. }\end{array}$ & $\begin{array}{l}\text { Ser uma catadora de } \\
\text { mangaba e pescadora como } \\
\text { os pais e as mulheres da } \\
\text { região. }\end{array}$ \\
\hline & $\begin{array}{l}\text { Dedicação e paixão em } \\
\text { promover a mudança. }\end{array}$ & $\begin{array}{l}\text { Satisfação em ajudar } \\
\text { as pessoas e } \\
\text { promover a igualdade } \\
\text { social. }\end{array}$ & $\begin{array}{l}\text { Vontade de reconhecimento } \\
\text { da importância das catadoras } \\
\text { e marisqueiras. }\end{array}$ \\
\hline & $\begin{array}{l}\text { Contribuir com a } \\
\text { mudança social das } \\
\text { mulheres da região. }\end{array}$ & $\begin{array}{l}\text { Contribuir com que a } \\
\text { população local } \\
\text { tivesse acesso a } \\
\text { moradia e assistência } \\
\text { do poder público. }\end{array}$ & $\begin{array}{l}\text { Contribuir com a mudança da } \\
\text { realidade da população e } \\
\text { preservação das plantas } \\
\text { produtoras de mangaba. }\end{array}$ \\
\hline
\end{tabular}

Fonte: Os autores (2015).

\section{Considerações finais}

Este estudo teve como objetivo, analisar as motivações de mulheres para criar empreendimentos sociais. É importante destacar que em todos os casos foi verificada a visão de solidariedade das empreendedoras e as necessidades de auxiliar a população das regiões em que viviam apesar das dificuldades financeiras e falta de conhecimentos.

O não planejamento formal anterior ao processo de operacionalização pode estar relacionado tanto ao grau de instrução e formação das empreendedoras, como

VAZ, V. H. S.; TEIXEIRA, R. M.; OLAVE, M. E. L. Empreendedorismo social feminino e motivações para criar organizações sociais: estudo de casos múltiplos em Sergipe. Revista de Empreendedorismo e Gestão de Pequenas Empresas, v.4, n.3, 2015. 
também com os recursos no processo de criação das organizações. Vale destacar o apoio da Universidade Federal de Sergipe através do departamento de Serviço Social, dado a estruturação dessas organizações sociais. Além disso, é preciso lembrar a importância dos agentes governamentais e públicos no apoio a essas instituições, tanto para suas criações quanto nas suas sobrevivências.

Para pesquisas futuras, sugere-se maior aprofundamento sobre 0 empreendedorismo social, principalmente com relação ao gênero, de forma a contribuir para uma melhor compreensão do papel da mulher como agente de mudança social.

\section{Referências:}

AUSTIN, J.; STEVENSON, H.; WEI-SKILLERN, J. Social and commercial entrepreneurship: same, different, or both? Entrepreneurship: Theory and Pratice Journal, da Baylor University, v. 30, n. 1, p. 1 - 22, 2006.

BIRLEY, S. Female Entrepreneurs: Are They Really Any Different? Journal of Small Business Management; v. 27, n. 1, 1989.

CALAS, M. B.; SMIRCICH, L.; BOURNE, K. A. Extending the Boundaries: Reframing "Entrepreneurship as Social Change" Through Feminist Perspectives. Academy of Management Review, v. 34, n. 3, p. 552 - 569, 2009.

CRESWELL, J. Research design: Qualitative, quantitative, and mixed methods approaches. London: Sage, 2002.

DATTA, P. B.; GAILEY, R. Empowering women through social entrepreneurship: case study of a women's cooperative in India. Entrepreneurship theory and practice, v. 36, n. 3, p. $569-587,2012$.

EINSENHARDT, K. M. Building theories from case study research. Academy of Management Review, v. 14, n.4, p. 532 - 550, 1989.

GARTNER, W. B. A conceptual framework for describing the phenomenon of new venture creation. Academy of Management Review, v.10, n.4, p. 696 - 706, 1985. 
Who is an Entrepreneur? Is the Wrong Question. Entrepreneurship Theory and Practice, n. 13, p $47-68,1989$.

GEM, Global Entrepreneurship Monitor. Empreendedorismo no Brasil 2005. Coord. BASTOS JR, Paulo Alberto; GRECO, Simara Maria S. S.; HOROCHOVSKI, Rodrigo Rossi; MACHADO, Joana Paula; SCHLEMM, Marcos Mueller... [et al]. Curitiba: IBQP, $2016.158 \mathrm{p}$.

Empreendedorismo no Brasil 2012. Coord. GRECO, Simara Maria de Souza Silveira; Aut.: ANDREASSI, Tales; MACEDO, Mariano de Matos... [et al]. Curitiba: IBQP, $2012.162 \mathrm{p}$.

GODOY, A. S. Pesquisa Qualitativa: Tipos Fundamentais. Revista de Administração de Empresas, v. 35, n. 3, 1995.

HUMBERT, A. L. Women as social entrepreneurs. 2012. 12 f. Working Paper 72, University of Birmingham, Birmingham, 2012.

LOW, M. B.; MACMILLAN, I. C. Entrepreneurship: Past Research and Future Challenges. Journal of Management, v. 14, n. 2, p. $139-161,1988$.

MACHADO, H. V.; ST-CYR, L.; MIONE, A.; ALVES, M. C. M. O Processo de Criação de Empresas por Mulheres. RAE-eletrônica, v. 2, n. 2, p. 1 -22, 2003.

MAIR, J. Social entrepreneurship: Taking stock and looking ahead. In. FAYOLLE, A.; MATLAY, H. Handbook of Research on Social Entrepreneurship, Edward Elgar: Cheltenham, 2010.

NISHIMURA, M.; ALPERSTEDT, G. D.; FEUERSHÜTTE, S. G. Empreendedorismo Social Feminino: Uma Pesquisa a Partir da História de Vida de Mulheres Empreendedoras. In.: XXXVI Encontro da ANPAD, 36, 2012, Rio de Janeiro. Anais... Rio de Janeiro: Anpad, 2012. p. 22 - 26.

ONOZATO; E.; TEIXEIRA; R. M. Processo de Criação de Organizações com Fins Sociais: Estudo de Casos Múltiplos na Cidade de Curitiba, Paraná. Contabilidade, Gestão e Governança, v. 13, n. 3, p. $38-52,2010$.

PEREDO, A. M.; MCLEAN, M. Social entrepreneurship: A critical review of the concept. Journal of World Business, v. 41, p. $56-65,2006$. 
ROSSONI, L.; ONOZATO, É.; HOROCHOVSKI, R. R. Criação de Empreendimentos Sociais Reflete a Atividade Empreendedora Nacional? Explorando as Relações entre Empreendedorismo Convencional e Social no Brasil. In.: Simpósio de Gestão, Inovação e Tecnologia, 24, 2006, Gramado. Anais... 2006, p. 17-20.

SAUNDERS, M.; LEWIS, P.; THORNILL, A. Research Methods for Business Students. 4. ed. England: Pearson Education, 2007.

SERGIPE. Lei 3.954, de 19 de agosto de 2010. Reconhece de utilidade pública a Sociedade Sergipana Monte Sião e dá outras providências. Diário Oficial [do] Município - DOM, Aracaju, Se, 25 ago. 2010. Disponível em: <https://leismunicipais.com.br/a/se/a/aracaju/lei-ordinaria/2010/395/3954/leiordinaria-n-3954-2010-reconhece-de-utilidade-publica-a-sociedade-sergipanamonte-siao-e-da-outras-providencias-2010-08-19.html>. Acesso em: 03 out. 2014.

SHANE, S.; VENKATARAMAN, S. The Promise of Entrepreneurship as a Field of Research. Academy of Management Review, v. 25, n. 1, p. 217 - 226, 2000.

YIN, R. K. Estudo de Caso: Planejamento e Métodos. Tradução Daniel Grassi. 2. ed. Porto Alegre: Bookman, 2001. 